stimulating book, betraying at times the author's prejudices and (by some errors) the speed with which it was written, but encouraging the reader to persevere and presenting difficult ideas with an effective style. Mr. Moroney is no doctrinaire theorist, but an exponent of methods that he has proved valuable in problems of industry and science; his book is packed with wise advice on the collection and interpretation of data, all of which is at least as important as the information on analysis. If the book has the wide currency that it deserves, it should do much to forward his contention that: "Whoever you are, if your work calls for the interpretation of data, you may be able to do without statistics, but you won't do so well".

D. J. FINNEY

\section{THE LOGIC OF INDUCTION}

A Treatise on Induction and Probability By Prof. Georg Henrik von Wright. (International Library of Psychology, Philosophy and Scientific Method.) Pp. 310. (London: Routledge and Kegan Paul, Ltd., 1951.) 30s. net.

THE author puts forward this. work somewhat diffidently as a contribution to the problem of induction, which since the days of Hume has presented a challenge to philosophers. The general title of the book is a little misleading, for Prof. G. H. von Wright intentionally restricts his discussion to the logic of inductive inference, as distinct from the problems of discovery and justification. To this end he introduces the methods of symbolic logic in Chapter 2, and discusses the logic of inductive truth in the following chapters. These include a chapter on the relation with deduction, in which the author considers the supplementary and often suppressed premises required to render induction demonstrative. In the second half of the book he goes on to discuss the logic of inductive probability, introduced in Chapter 7 by an axiomatic development of probability logic. $\mathrm{He}$ adds here a fairly complete list of the various possible interpretations of probability, though for the frequency interpretation he seems to be most familiar with the direct definitions of von Mises or Reichenbach. Many statisticians, including myself, prefer the relation with frequency to be made finally precise by the theoretical laws of large numbers. For example, need a sequence defining a probability value be completely random ? The probability calculus itself tells us that the answer is no; all that is required is that the sequence should be ergodic.

The carefully limited aim of this book disarms criticism, for the author is an acknowledged expert on inductive logic ; it can nevertheless be occasionally irritating. The author often shows his awareness of problems, difficulties or alternative approaches, only to dismiss them as lying outside his chosen field. This isolation of one's subject-matter is admissible up to a point, but seems dangerous with the problem of induction, which is linked so inextricably with other philosophical problems, such as causality and the nature of scientific laws. The author distinguishes two kinds of induction: those of the first order or predictions, and those of the second order or theories. $\mathrm{He}$ mentions statistical laws, but does not claim to discuss them at length. Yet Eddington has suggested that, apart perhaps from statistical laws, the laws of Nature are epistemological in character and purely deductive. Again, von Wright adopts as one of his basic axioms in Chapter 2 that every proposition is true or false. Are scientific laws true or false, or merely instruments of prediction of greater or lesser success? And what of three-valued logic--truth, falsehood and indeterminacy - which Reichenbach has claimed avoids causal anomalies in quantum mechanics? Such queries may be answerable (there is, for example, some relevant discussion in Chapter 6 on the inter-relation of induction and definition), and in any case do not affect the validity and permanent value of von Wright's logical analysis. But they do perhaps support the reviewer's, and apparently also the author's, view that a discussion on such classical logical lines may be unduly limited.

This book seems to be intended for professional logicians, who will find in it much acute argument, rather than for general readers, among whom I would class myself. My own inclination would have been to defer such a strictly logical discussion until a more complete general discussion had been attempted, in order to avoid the danger of (to quote the author's own words) "oversimplification and ... the assimilation of cases to general patterns which they do not really fit". For comparison, the discussion of induction and probability contained in Bertrand Russell's work "Human Knowledge" is for the layman much more readable. Incidentally, von Wright is a little unlucky that his book was completed in 1948, just as Russell's book was published; and he is only able to refer to it (and also to recent work by Carnap) in his final paragraphs.

M. S. BARTLETT

\section{A STUDY OF CHORDATES}

\section{Vertebrate Zoology}

An Introduction to the Comparative Anatomy, Embryology and Evolution of Chordate Animals. By Dr. G. R. de Beer. (Text-Bopks of Animal Biolcgy.) New edition. Pp. $x v+435$. (London: Sidgwick and Jackson, Ltd., 1951.) 32s. 6d. net.

TEARLY a quarter of a century has elapsed since Dr. G. R. de Beer, then a young lecturer in the Oxford Department of the great E. S. Goodrich, published the first edition of his "Vertebrate Zoology", and it has since become one of the foremost introductory text-books in British countries. It has become so with good reason. The book sets out briefly and with great lucidity the essential morphology, embryology and comparative zoology of the various chordate types that all of us studied in our first enthusiastic plunge into the discipline of formal biology.

This new edition, as with the various impressions of the last, deals first with morphological types (including Ceratodus); secondly with the four usually used embryological types; thirdly (in the form of a series of short essays) with the comparative zoology of structures such as the skin, fins and limbs, the alimentary system and so on; and fourthly with aspects of evolutionary morphology, including a short separate account of the evolution of the Primates. There is an excellent short chapter on the origin of the Chordates. Finally, there is a classification of the animals previously dealt with.

The chapters dealing with the introductory morphology, embryology and comparative anatomy are admirable, and the illustrations, labelled with 